\section{Social responsibility for new technologies}

A 2013 report by the European Environment Agency analyses a range of chemical and technological innovations and the long-term effectiveness of policies designed to minimize risks to health and the environment resulting from their use (see go.nature.com/ajxkkt). As contributors to the report, we call for more proactive forms of governance to incorporate greater social responsibility in new technologies.

The report shows that, rather than stifling innovation, preventive policies can promote investment in safer alternatives and in managing risk. When precautionary regulatory action was taken on the basis of plausible yet incomplete evidence of harm, cases of over-regulation were rare. More often, such action was later shown to be justified.

Twenty case studies of potential hazards - including leaded petrol, nicotinoid pesticides (recently banned in Europe) and mercury pollution - reveal that current risk-assessment standards often prevent or delay the detection of risks. Given the number of emerging technologies that will require safety appraisal, future risk assessments will need to adopt solutions-oriented strategies that increase timeliness and efficacy.

The complex issues around emerging technologies, such as genetically modified crops, call for greater social responsibility by scientists, and for regulators to seek advice from the wider community to address safety concerns and establish principles for sustainability, utility and acceptable risk early on.

Incentives and fiscal advantages, such as public procurement, will encourage industry to adopt responsible measures. These will require social criteria to be captured in processes for public research funding, backed by an updated definition of scientific excellence.
Jacqueline McGlade

European Environment Agency, Copenhagen, Denmark.

jacqueline.mcglade@eea.europa.eu

David Quist GenØk, Trømso,

Norway.

David Gee London, UK.

\section{Preserve our digital heritage}

Last month saw the sudden end of Yahoo! Messages, a valuable 15-year-old treasure trove of early Internet discussions. Luckily, Archive Team, a group dedicated to saving our digital heritage, was able to preserve the data. But we need to be more vigilant over the erosion of our digital archives (see also Nature 493, 19-21; 2013).

For instance, Yahoo!'s

closure of GeoCities in 2009 was described by the Internet Archive as destroying "the most amount of history in the shortest amount of time, certainly on purpose, in known memory".

Archives of paper documents have been preserved for centuries, and their destruction promotes a strong response (see, for example, go.nature.com/gstbwk). Ditching online archives fails to stimulate similar reactions.

Researchers should publicly question the deletion of digital archives. We can all take part by contributing to the Internet Archive or Archive Team Warrior initiatives, or by learning more through sites such as the digital preservation blog of the US Library of Congress.

Ian Milligan University of Waterloo, Ontario, Canada. i2milligan@uwaterloo.ca

\section{An innovation prize for clean cookstoves}

A radical shift in engine technology in the 1970s (Honda's CVCC) drastically cut motorvehicle emissions. A comparable game-changer could solve an even bigger pollution problem today.

Household air pollution from the traditional biomass-burning stoves used in many developing countries is the world's largest environmental-health threat, leading to 4 million premature deaths annually (S. S. Lim et al. Lancet 380, 2224-2260; 2012). We propose that a multimilliondollar innovation prize should be set up, funded by governments or private philanthropy, to rapidly bring cleaner, more efficient and affordable stoves to poor people.

The competition would attract the world's best combustion scientists and engineers, and would help to take the current efforts of non-governmental organizations, small companies and academics to the next level (see S. Anenberg et al. Nature 490, 343; 2012).

The prize would be awarded for a durable, low-emission biomasscombustion unit - the 'heart of the hearth' - rather than for the stove itself. Stove designs could then be adapted around this to meet local requirements.

Ambuj D. Sagar Indian Institute of Technology Delhi, India. Kirk R. Smith University of California, Berkeley, USA. krksmith@berkeley.edu

\section{No mass strandings since sonar ban}

Prompt political action may have resulted in a remarkable conservation success for whales and dolphins. The Canary Islands used to be a hotspot for mass strandings, but there have been no mass beachings since the Spanish government imposed a moratorium on naval exercises in these waters in 2004.

Naval sonar operations have long been implicated in mass strandings, particularly of beaked whales (R. Filadelfo et al. Aquat. Mamm. 35, 435-444; 2009). In 2002 , the stranding of 14 beaked whales in the Canary Islands was linked to the use of midfrequency naval sonar in the area (P. D. Jepson et al. Nature 425, 575-576; 2003). In 2004, four Cuvier's beaked whales (Ziphius cavirostris) were stranded there after an international naval exercise (A. Fernández et al. J. Mar. Sci. Res. Dev. 2, 2; 2012).

These events prompted the Spanish moratorium and led the European Parliament to issue a non-binding resolution in 2004 to stop the deployment of high-intensity sonar until the completion of a global assessment of its cumulative effects on marine life.

Antonio Fernández, Manuel Arbelo University of Las Palmas de Gran Canaria, Spain. afernandez@dmor.ulpgc.es Vidal Martín Society of Cetacean Studies in Canary Islands (SECAC), Lanzarote, Spain.

\section{Japan's work on ALMA telescope}

Your report on the Atacama Large Millimeter/submillimeter Array (ALMA), the world's highestaltitude radio telescope, omits mention of Japan's contribution (Nature 495, 156-159; 2013).

The National Astronomical Observatory of Japan (NAOJ) is one of three executive partners of ALMA and is in charge of implementing East Asia's contribution to the array.

Japan did not simply "join the partnership in 2004" (see D. Normile \& D. Clery Science 333, 1820-1823; 2011). As long ago as 1983, Japan put forward plans for the Large Millimeter Array (LMA), almost at the same time as the US National Radio Astronomy Observatory proposed the Millimeter Array. Japan was the first to suggest expansion of the observation wavelength to the submillimetre range in 1987, renaming the LMA as the Large Millimeter and Submillimeter Array (LMSA). It was also the first country to start site surveys for millimetre/ submillimetre-wavelength interferometers around the current ALMA site in northern Chile in 1992.

Masahiko Hayashi, Satoru Iguchi NAOJ, Tokyo, Japan. masa.hayashi@z.nao.ac.jp 